\title{
Making ideas "app"-en: The creation and evolution of a digital mobile resource to teach social work interviewing skills
}

\begin{abstract}
This paper describes the processes involved in the design, delivery, and evolution of a mobile app.' The initial app' was funded by an institutional Teaching Award to update the delivery of Egan interviewing skills to social work students. The article charts the progress of development, beginning with the initial rationale for the app' and its subsequent evolution into a Motivational Interviewing resource for social workers within a designated local authority. Arguing for the increasing importance of digital resources, within social work training and practice, the article draws from theories of digital pedagogy, as well as highlighting the work of some prominent figures within this emerging field. The article is written as a collaboration between the lead author and the app' developers, who have contributed technical detail and emphasized the need for collaboration. Whilst the article touches briefly on the mechanics involved with app creation, its chief aim is to act as a guide to the practical, financial and relational aspects of development-in order that other social work practitioners and educators are inspired to progress their own ideas into innovative digital resources. To facilitate this, the article concludes with a practical list of suggestions for successful digital development
\end{abstract}

KEYWORDS: Mobile resources; digital collaboration; app development; interviewing skills; technology-assisted communication; technology; collaboration; organizations; blended learning

\section{Introduction}

This article describes the design, delivery and evolution of a mobile app, created initially for teaching Egan interviewing skills, within a UK higher education institution (HEI). The article focuses on the processes involved in transforming the initial idea into a product and subsequently the evolution of this product into a mobile resource, to enhance motivational interviewing skills. Like the development process itself, the article is collaboratively authored, with the app developers contributing technical details and emphasising the need for flexibility and trust within the development relationship. The article touches on the technicalities involved in app creation, but deliberately does not dwell on these, choosing instead to act as a means of encouraging social work practitioners and educators to develop their own ideas into innovative digital resources. The article also aims to act as a guide to the challenges and unexpected bonuses of participating in digital development, even for those who, like the lead author, consider themselves technologically challenged.

It is estimated that two thirds of the global population are currently connected to mobile devices, making a total of approximately five billion subscribers worldwide. This figure is predicted to rise, so that by $2020,75 \%$ of the global population will be connected via mobile resources (Hollander, 2017). This rapid increase in digital connectivity has changed every aspect of people's lives, fundamentally altering the ways in which we live, work and relate to each other. Average attention spans have diminished, with the typical adult able to watch only seven minutes of a television programme before reaching for a mobile device (Elsworthy, 2017), whilst for children and young people in the UK the split between the "real world" and the digitally mediated environment is increasingly bogus 
(Ofcom, 2016). Some $67 \%$ of five to seven-year-olds now use a mobile device regularly, thereby rendering digital networking the new normal for contemporary youth. As these young people develop into the next generation of undergraduates, they expect approaches to teaching and learning that mirror their experiences. However, as Wheeler (2015) cautions, there is a "contemporary clash of cultures" (p. 9) within higher education, whereby new expectations may not sit comfortably with old mindsets.

Reamer (2013) suggests that the nature of social work practice has also been completely transformed by both the rapid rise and the consequences of digital technology. The latest updates to the Standards of Proficiency support this, requiring practitioners to "demonstrate a level of skill in the use of information technology appropriate to their practice" (Health and Care Professions Council [HCPC], 2017a p. 13).

The initial idea for updating teaching via the use of digital technology was inspired by this rise in online technologies and their consequent impact on the landscape of social work education and practice (Ellaway, 2010).

\section{Social work and digital practice}

Within social work education and practice, interaction with the digital world raises a number of acknowledged challenges (Turner, 2016; Cooner, 2014; Cooner, Knowles, \& Stout, 2016).

Rafferty (2014) traces social work's first meaningful engagement with digital technology back to 2003 and the "old 'new' social work degree" (p. xi). Since then, some social work academics have started to engage with the opportunities and challenges made possible by the online world, whilst both the British Association of Social Workers (BASW) and the HCPC have produced updated guides for social workers to inform their use of social media platforms (BASW, 2018; HCPC, 2017b). However, in a Freedom of Information request, Schraer (2015) found that, despite such guidelines, social workers often feel out of control around online sites and want more training and support in order to help them navigate an increasingly complex online landscape.

Within social work education, Kellsey and Taylor (2017) argue that institutional practices such as banning mobile phone use within the classroom result in a further loss of "opportunity to develop digital literacy relevant to education and to future employment" (p. 29). This argument is echoed by Cooner et al. (2016, p. 247), who cite official policy on a social work qualifying programme that actively discouraged students from using social media. Cooner (2004) further emphasises the importance of social work educators keeping pace with technological change in order that as "a profession... we do not, through a lack of awareness caused by apathy, or ignorance caused by fear, simply accept the changes technology may bring" (p. 733).

Previous research by the lead author (2016) demonstrated how important Cooner's caveat is in relation to newly qualified social workers entering the field. One practitioner in her Assisted and Supported Year in Employment who was asked to participate in a study of social media use responded initially by saying she was "technophobic" and therefore did not want to take part. On reflection, she agreed to participate, realising that "[i]t is highly likely I will encounter this in practice" (Turner, 2016, p.322) and consequently that she needed to apprise herself, rather than stumbling uninformed into areas she did not understand. 
Cartwright (2017) also points to the need to "up skill the existing workforce" (p. 882), whilst trends from the wider employment field further highlight the wisdom of improving digital awareness.

Wheeler (2015) states that "teachers are now preparing students for a world of work that has yet to be invented" (p. 12), whilst the Science and Technology Committee (2016) found that approximately $72 \%$ of employers would not interview prospective employees who did not have basic IT skills. Susskind and Susskind (2015) argue further that we are on the brink of a "post professional society" (p. 105) in which online learning may eventually oust the traditional HEI.

Results from the four focus groups that formed part of the Egan app development process showed that practitioners and students alike were keen to respond to the challenges of the digital world and develop ideas in interactive ways. Like the lead author, a proportion of social work academics may lack the necessary technical skills to develop these creative ideas into an app, but the experience mapped within this article shows how these ideas can be realised through collaborations, which also mirror the fundamental values of social work.

\section{The Egan Model}

The Egan model has been a central part of many social work education programmes for decades, offering a "problem-management model" that follows a cognitive behavioural approach to resolving difficulties (Egan, 2014, p. 8). Within the model there are three stages, designed to move service users towards strategic solutions and achieving goals. Stage 1 identifies and clarifies the presenting problem, whilst Stage 2 helps the service user to develop a preferred scenario. The final stage, moves towards this scenario through deliberate action (Egan, 2014, p. 31). Skills including active listening and empathic responding are used throughout the three stages (Egan, 2014).

The model is typically taught on social work programmes via role play, with students interviewing each other in front of their peer group and lecturers, who subsequently provide feedback. In the lead author's host institution at the time of the app development, the Egan model was taught to both postgraduates and undergraduates, with the sequence occupying the best part of a semester, via a process that had remained unchanged for decades.

This use of the Egan model as a fixture within many social work education programmes has recently been reviewed and critiqued (Riggall, 2011, 2015). Riggall's (2015) evaluation of the model's sustainability within social work education found that it was very valuable in teaching initial communication and problem management skills to students, which they then transferred to practice. Students in Riggall's study (2015) also reported that the role plays in which they often participated reluctantly were crucial in embedding their learning from the model. At the lead author's institution at the time of developing the Egan app, these role plays were initially carried out by lecturers interviewing each other in front of the student group. In later weeks students were paired, with the two members of each couple then interviewing each other, whilst being filmed. The resulting video was subsequently used as a means by which students could formally appraise their performance, using process recordings or similar written accounts (Riggall, 2015).

In her studies of the Egan model, Riggall (2015) suggests that the challenge for social work educators lies in helping students to maintain the skills they learn after teaching has ended. The app acted as a response to this challenge, offering students a reminder of the model whenever they were feeling de-skilled, thereby increasing confidence and improving potential outcomes for service users (Riggall, 2015). 


\section{Theoretical foundation and rationale}

Wheeler (2015) counsels firmly against utilising technology because "it's new and shiny or because everyone else is doing it" (p. 7), arguing instead for sound theoretical foundations to underpin digital pedagogy. In social work, where the adoption of new technological practices has been slow (Cooner, 2004), it can be argued that "everyone else is [not] doing it" although, as discussed, there is a gradual increase in the number of social work academics and practitioners becoming involved with new forms of digital and mobile learning (Turner et al., 2016; Cooner, 2010; Cooner et al., 2016; Kellsey \& Taylor, 2017). Nevertheless, Wheeler's caveat is an important one, and in developing any form of digital resource for social work education and practice there must be a sound theoretical basis, rather than an excited response to contemporary trends.

In describing the development of an app to teach social media to student social workers, Cooner et al. (2016) outline how they utilise the cognitive and situational approaches as their underpinning theoretical foundation (Mayes \& De Freitas, 2004). In the cognitive approach, learners are required to use experimentation, observation and reflection in creating a personal learning experience, rather than their experience simply being absorbed from external sources (Cooner et al., 2016). The situational approach focuses on the importance of links between the learning task and its application to real life (Cooner et al. 2016). In using these theories, the authors aim to make their app experiential, rather than one that simply delivers knowledge.

Campbell and McColgan (2016, p. 300) describe developing four social work education and practice apps, underpinned by three theoretical perspectives: defining mobile learning, theory of mobile learning and developing communities of practice. Defining mobile learning includes the means by which mobile devices make learning accessible outside traditional classroom spaces, thereby creating new opportunities and virtual communities of practice.

In their paper on the use of Twitter, Marwick and boyd* (2010) introduce the concept of "context collapse", which has now been widely adopted within the emerging field of digital theory. Context collapse speaks to the notion of mobile learning by suggesting that there are no boundaries left between the public and the private, just as there are permeable walls between formal and informal learning spaces.

This concept of context collapse and the model of mobile learning were crucial to the design of the Egan app, in order that knowledge and skills were accessible outside the classroom. The mobile nature of the app responded directly to Riggall's challenge of helping students maintain the skills they learn after teaching has ended (2015). Drawing from the 2016 Ofcom research too, it is clear that contemporary learners do not erect boundaries around learning spaces, but rather expect the acquisition of knowledge to be both mobile and perennially accessible. This was emphasised in initial focus group meetings with students, who reinforced the utility of having knowledge and advice available in a mobile form.

Theoretically, utilising the app in this way also mirrors Hase and Kenyon's theory of "heutagogy" (Hase \& Kenyon, 2007). Heutagogy proposes that people inherently know how to learn and are driven to do so. Within this paradigm, learning is often informal, driven by personal need and, as with context collapse, blurs the boundaries of formal and informal contexts (Wheeler, 2015).

Rapid advances in digital technology have led to a multiplication of theories such as heutagogy, which strive to capture the pedagogical changes wrought by technology. Often, resources develop in the same way as Facebook and other platforms, as a response to a particular problem, and then catch the public imagination, which causes them to spread worldwide (Kellsey \& Taylor, 2017). 
Kellsey and Taylor (2017), in their work on digital pedagogy, illustrate how new advances in communication have perennially tended to be sporadic, emerging as a response to different needs. In terms of the app development, it was the lead author's desire to update and enhance the mode of delivery that first inspired the idea. However, after speaking to students in initial focus groups about the viability and application of the app, it became clear that it could be moved outside the classroom into the world of practice

\section{Development of the app and content creation}

Cooner (2004) suggests that despite increasing interest in the online world within social work education, there has been little specific focus on the role that digital mobile devices can effectively play in teaching social work students. Within the initial focus group for the app, integration of the Egan model into their mobile phones was the most popular choice amongst students, who unanimously rejected any form of incorporation within the institution's online learning platform. Students were clear that they used this platform only when they needed to access module resources, because they generally found it outmoded and cumbersome. As they chiefly interacted through Whatsapp groups, the online forums were not widely used.

Any app development process also requires funding, and the more sophisticated the intended product, the more funding will be required. In the case of the Egan app, the lead author was awarded an institutional Teaching Excellence Award of $£ 5,000$, which provided sufficient funds to hold four student-led focus groups and design a prototype. At this stage, the main driver was to create a mobile resource that could be used in teaching the Egan sequence. However, once funding had been secured, it was necessary to select a firm of app developers to move the initial idea into some form of realistic product. In their article on developing apps, Campbell and McColgan (2016) highlight the "two relatively unconnected social work and IT sectors" (p.305), which was a concern for the lead author at the start of the app development process. Having devised the idea of the app and with some idea of what she wanted to achieve, the lead author was concerned both about her own lack of technical expertise and that IT experts would be unable to grasp the nuances and complexities of social work practice and education. Campbell and McColgan (2016) provide a checklist of developmental guidelines for professionals interested in app development, which advises building "a mutually respectful working relationship with your developer company" (p. 308). In order to try to achieve this, the lead author chose to contact a local business that had been personally recommended to her and which had years of experience in the field of digital education.

After the first meeting it became clear that the lead author's fear of being unable to unite the "two relatively unconnected" worlds of social work and IT was misplaced (Campbell \& McColgan, 2016, p. 305). However, this also highlights how choosing the right app developer for your needs is crucial to any app development project. This is also particularly vital where, as with the Egan app, the initial idea arises from a combination of curiosity and drive for pedagogical enhancement, rather than from any level of IT literacy, or clear developmental trajectory. The developers were able to fully understand the needs of the project and brought to it their experience in the educational field, as well as their obvious digital expertise. This kind of working collaboration is therefore key to the success of any digital collaboration.

In order to test the need and potential for an Egan app, focus groups were chosen as the form of interaction most appropriate to the development. Focus groups invited the real-world experiences 
of participants (Cartwright, 2017) and could be opened to anyone who wanted to attend. An open invitation was extended, and four focus groups were eventually held. The numbers were different on each occasion, as the invitation was deliberately inclusive. However, a core group of students attended throughout the focus group process and the lead author was present on each occasion to ensure consistency. Students from both the undergraduate and postgraduate programmes attended, with one group reaching a maximum of twenty attendees. Focus groups were audio recorded and key points transcribed in order to inform the practicalities of development. In addition to the focus groups, feedback was sought from three representatives of the service user and carer network at the host institution, one of whom was involved in filming video for the app. Faculty were invited to join the focus groups, or to contribute ideas, but they proved harder to engage. In the context of involving social work staff with technology and online interaction, Cartwright (2017) identifies a "gap that may exist between teaching staff and the students they work with" (p. 887), a phenomenon that was demonstrated in the initial app development. Two faculty members did however agree to be involved in filming, along with a service user and the lead author.

Drawing from feedback from the first focus groups, the initial prototype app featured video examples of staff and service users utilising the Egan method in three different interview scenarios. These videos formed the hub of the learning and were supplemented by swipe screens that provided access to text explaining the Egan model stages and underpinning theory. The videos themselves were also available in different versions, offering learners the opportunity to pause the interviews; to watch the interviews as a whole, or to watch them with annotated text explaining the different stages.

On the technical front, the initial prototype app utilised LiveCode, a software development environment that enables fast production of cross-platform digital resources. This allowed for the development of the prototype app with a single code-base that worked across both iOS (Apple) and Android (Google) operating systems. It also enabled easy instigation of changes and updates in response to feedback from focus groups and other events. The overall design and means of navigating the app were made deliberately simple, allowing users to get quickly and efficiently to the content they needed. This simplicity also meant that the design transferred readily between different platforms (iOS and Android) and devices (mobile and tablet), as well as allowing updates that would be unlikely to "break" the app and easing maintenance of the app over time.

The interactive video could be viewed in different modes, all of which could be installed on the user's device. This meant that, following installation, users did not need to be "online" to access and interact with the app content, thus enabling use of the app "anywhere, anytime".

The prototype app was trialled in two additional focus groups, with social work students and those in their Assisted and Supported Year in Employment (ASYE), and as a result was further updated and refined. From these initial trials, it became obvious that the app, initially designed for teaching the Egan method, might have the potential to support students through their ASYE, and beyond.

Following the focus groups and initial development of the prototype, the app was utilised within the first semester of the postgraduate module "Theories, Methods and Values in Practice", which is where much of the Egan interviewing took place. The lead author recorded student feedback, which was very positive. In particular, compared with the previous method of staff interviewing each other to showcase the model, students universally preferred the use of the Egan app. One of the key reasons for this was that the practice of lecturers modelling Egan skills did not allow for the power imbalance between staff and students and thereby made it difficult for students to give honest feedback. When using the app, however, critique was easier, as the interviews were not taking place 
live in the room, whilst the use of video made it possible for students to pause at key points and ask for clarification or add comments. Additionally, feedback showed that students found it easier to learn from flaws in the interviewing process, which were exposed by the videos, rather than from watching staff attempting to stage a perfect live performance. This feedback echoes that discovered by Cooner et al. (2016, p. 252), in which the interactions enabled by digital resources were viewed very favourably in comparison with older versions of delivery.

The pilot Egan app was also showcased at a highly successful Higher Education Innovation Fund training day run by the lead author, which took place in 2016 at her previous institution. Delegates to the day were drawn from social work students, local authority practitioners and other stakeholders, and the app presentation formed part of a mixed programme of digital activities and resources. The reaction to the app, particularly amongst practitioners, was effusive, as this sample of feedback in response to the questions "What was best about the day?" and "Any other comments?" illustrates:

- THE EGAN APP!! This was tremendous and could really impact on social work (even other areas)

- Apps that reinforce positive practice skills would be useful to us as practitioners

- Our own ideas can be developed into positive resources like the Egan app - DON'T BE AFRAID TO BRING IDEAS FORWARD (there are IT people who can help you develop)

Following the positive reception of the pilot app, the lead author was successfully awarded further institutional funding to commission a market analysis of the use of apps within social work practice and education (Sussex Innovation Centre, 2016). This was a mixed-methods study, which scoped the contemporary use of apps and other digital resources in social work education. Findings from the analysis emphasised the lead author's original hypothesis that there were very few social work apps on the market, although this was slowly starting to change. The analysis further highlighted that many of those apps that had been produced specifically for social work were practice led, suggesting that the profession was gradually adapting to the need for digital learning and competency (Sussex Innovation Centre, 2016). Whilst the Egan, "Skilled Helper" model was used widely in social work education, the market analysis showed that there were no apps related to this model on the market for use in either practice or education.

Finally, the market analysis indicated that the next steps in developing the app should include a consultation with practising social workers and managers. Whilst the original idea for the Egan app had been driven by the lead author, the market analysis demonstrated much wider potential for social work app development, extending into alternative techniques and methods.

\section{Working with stakeholders - promotion and advancement of the app}

Following trials in the classroom, faculty at the host institution were largely dis-interested in embedding the app in their own teaching, a phenomenon also observed by Cartwright (2017). However, indications for development from the market analysis led to meetings with Principal Social Workers in the neighbouring local authorities. Whilst they were excited by the app, feedback from these meetings demonstrated that the Egan model was not widely used in practice. The feedback showed that, in development terms, a motivational interviewing model may hold greater potential for practitioners than the Egan model, which is arguably more applicable to initial social work education (Greeno, Ting, Pecukonis, Hodorowicz, \& Wade, 2017; Wahab et al., 2015). 
This iterative process highlights the democratisation of learning, which was one of the unexpected outcomes of the Egan app development process. As Kellsey and Taylor (2017) discuss, this process of collaboration is not new to social work education. However, prior to the development of digital resources within the classroom, this peer collaboration was largely confined to the classroom environment or the individual institution and tended to be dependent on the knowledge of individual lecturers (Kellsey \& Taylor, 2017). The advent of digitisation has opened learning opportunities, not just for students but for academics, as knowledge is now shared through a proliferation of professional learning networks (Kellsey \& Taylor, 2017).

In their development of an app, Campbell and McColgan (2016) also highlight this democratisation, as their original idea was altered after discussions with students, practitioners and service users. Designing and developing the Egan app was a very particular example of such group learning. Beginning with the lead author's drive to create a new mode of delivery, the pilot version then led, through practice stakeholder involvement, to an entirely new app idea, focusing on motivational interviewing, or MI.

Although a detailed discussion of $\mathrm{MI}$ is beyond the immediate scope of this paper, its popularity in practice has been steadily increasing since the 1980s (Greeno et al., 2017; Miller \& Rollnick, 2013; Wahab et al., 2015). Miller and Rollnick, the pioneers of MI, describe the method as a "[c]onstructive way through the challenges that often arise when a helper ventures into someone else's motivation for change. In particular, MI is about arranging conversations so that people talk themselves into change, based on their own attitudes and values" $(2013$, p. 4).

The popularity of MI within social work practice has led to a robust body of evidence that supports its effectiveness as a model, whilst positive change can also be achieved within shorter timescales, when compared with results from similar models (Greeno et al., 2017; Wahab et al, 2015).

Additionally, $\mathrm{MI}$ is applicable to and widely used in a variety of social work settings including health, domestic violence and eating disorders (Miller \& Rollnick, 2013; Wahab et al., 2015), thereby increasing its applicability across social work practice.

Responding to feedback from practice required transforming the Egan app into an MI resource, which, in turn, required further funding. At this time, the lead author gained further funding through another Teaching Excellence Award which paid for the initial work. Fortunately, the navigation and balance of content of the Egan app prototype provided a sound environment for this new development. The basic structure and software remained essentially the same, with new content being developed using MI as the subject matter. This further demonstrated the versatility and appropriateness of the development environment, as new content was easily added to the existing app structure.

For this phase of the development, the developers worked with the neighbouring local authority and an $\mathrm{Ml}$ expert to develop a new interview scenario. This consisted of an initial interview and a follow up, acted out by the MI expert as the interviewer. Information on the app was also updated to cover the theory aspects of MI.

The local authority provided further funds to develop this MI prototype app, using professionally acted and filmed scenarios to create a fully formed app. This app has now been made available to all the local authority social workers for review, with plans to preload the app onto new iPhones being provided to local authority children and families social workers during 2019. 
As this version of the app was developed from a prototype and is being used with a specific target group, it is not available on either the Google Play Store or the Apple App Store at this time. The ultimate aim is to create a subscription-based distribution, which will require organisations (local authorities or HEls) to register and then distribute the app to their students/practitioners. At this point, the app will be available via the Play and App stores.

The process involved in initially conceiving the app to meet a certain purpose and subsequently watching it grow into a mobile resource that directly responds to the needs of social work practitioners has also triggered a transformation in the lead author's own professional development. Formerly something of a "luddite" (Turner, 2014, p. 64) but with a perennial interest in creative pedagogies, the app development process opened a new world of possibility for the expression and sharing of ideas, as well as the production of physical resources that respond to both changing patterns of learning and practice requirements.

\section{Conclusion}

This article has described the creation, evolution and future application of a software app initially developed to teach Egan interviewing, on a social work programme at the lead author's former institution. The article has emphasised that a lack of technological skill should not dissuade social work educators from translating creative pedagogical ideas into new digitally focussed resources. Like Cooner et al. (2016), our aim in this article has been to encourage "other educators [to] develop similar projects" (p. 268), whilst contextualising the need for this within an increasingly technologically driven society. In the demanding and competitive environment of higher education, it can be difficult for educators to respond to this invitation and to find time for their own learning and development. This in turn may lead to lethargy or disenchantment with the sector (Cooner, 2004). However, Wheeler (2015) suggests that "every successful teacher must also be a professional learner" (p. 18), and this article has attempted to show how the development and evolution of the app has contributed to this, whilst also responding to the growing need to embrace digital methods within social work education and practice (Turner, 2016; Turner et al., 2016; Cartwright, 2017; Cooner, 2010; Cooner, 2014; Kellsey \&Taylor, 2017).

In their description of developing apps for use in social work, Campbell and McColgan (2016, p. 307) provide a set of guidelines for social work educators and practitioners interested in developing their own mobile digital resources. Our experiences of designing and developing the Egan app endorse their recommendations, and to conclude we have provided our own list of recommendations, as a guide to all those who are inspired to develop their ideas for digital mobile resources:

- Be aware of the potential costs of app development. In the case of the Egan app, described in this article, the lead author was awarded various sums of money as an accolade for her teaching, through several Teaching Excellence Awards. In total, the cost of the pilot app and all further developments, including the initial stage of the motivational interviewing app, were funded by the lead author's Teaching Awards, at a cost of $£ 13,000$. This included all the focus groups, stakeholder involvement and market analysis, as well as the production costs of the pilot apps themselves. However, it is worth stressing that this is not a realistic cost in competitive terms. Again, it is the relationship with the app developer and the potential of both the partnership and the resources that will determine how much risk any developer is prepared to take in order to champion new and potentially profitable digital resources.

- Throughout the design and development phases stakeholders should be involved wherever possible in order that the app is responsive to actual need rather than being a reaction to the "new and shiny" (Wheeler, 2015, p. 7). 
- Collaboration between the lead academic, stakeholders and the developers should model social work values and be democratic and mutually respectful, regardless of different levels of technical prowess. Ideas should also be valued alongside technical ability and authority.

- Do not try to incorporate every suggestion but remain respectful and responsive to the practice and educational needs highlighted by service users, students and practitioners.

- Negotiate any relevant intellectual property issues from the outset, including the potential for signing non-disclosure agreements.

- Plan a strategy for updating the app and maintaining the information so that it remains responsive to the relevant needs.

- - Create a process for evaluating the effectiveness of the app and ensure that any updates are responsive to the needs of app users. 


\section{References}

British Association of Social Workers. (2018). BASW policy: social media. Retrieved from https://www.basw.co.uk/resources/basws-social-media-policy

Campbell, A., \& McColgan, M. (2016). Making social work education app'ier: The process of developing information-based apps for social work education and practice. Social Work Education, 35(3), 297-309.

Cartwright, L. (2017). Supporting students to use social media and comply with professional standards. Social Work Education, 36(8), 808-892.

Cooner, T. S. (2004). Preparing for ICT enhanced practice learning opportunities in 2010-a speculative view. Social Work Education, 23(6), 731-744.

Cooner, T. S. (2010). Creating opportunities for students in large cohorts to reflect in and on practice: Lessons learnt from a formative evaluation of students' experiences of a technologyenhanced blended learning design. British Journal of Educational Technology, 41, 271-286.

Cooner, T. S. (2014). Using Facebook to explore boundary issues for social workers in a networked society: Students' perceptions of learning. British Journal of Social Work, 44, 1063-1080.

Cooner, T. S., Knowles, A., \& Stout, B. (2016). Creating a mobile app to teach ethical social media practices. Social Work Education, 35(3), 245-257.

Cotter, E. (2015, April 23). Teens and tech: What happens when students give up smartphones? The Guardian. Retrieved from www.theguardian.com

Egan, G. (2014). The skilled helper: A problem management and opportunity development approach to helping (10th ed.). Pacific Grove, CA: Brooks/Cole Cengage Learning.

Ellaway, R. (2010). eMedical teacher. Medical Teacher, 32(8), 705-707.

Elsworthy, E. (2017, December 28). Average British attention span is 14 minutes, research finds. Independent. Retrieved from www.independent.co.uk

Greeno, E., Ting, L., Pecukonis, E., Hodorowicz, M., \& Wade, K. (2017). The role of empathy in training social work students in motivational interviewing. Social Work Education, 36(7), 794-808.

Hase, S., \& Kenyon, C. (2007). Heutagogy: A child of complexity theory. Complicity: An International Journal of Complexity and Education, 4(1), 111-118.

Health and Care Professions Council. (2017a). Standards of proficiency: Social workers in England. London: Health and Care Professions Council. Retrieved from https://www.hcpcuk.org/resources/standards/standards-of-proficiency-social-workers-in-england

Health and Care Professions Council. (2017b). Guidance on the use of social media. Retrieved from http://www.hcpc-uk.org/registrants/socialmediaguidance/

Hollander, R. (2017, September 19). Two-thirds of the world's population are now connected by mobile devices. Business Insider. Retrieved from http://uk.businessinsider.com

Kellsey, D., \& Taylor, A. (2017). The learning wheel: A model of digital pedagogy. St Albans, UK: Critical Publishing. 
Marwick, A., \& boyd, d.*(lower case is author's). (2010). I tweet honestly, I tweet passionately:

Twitter users, context collapse and the imagined audience. New Media and Society, 13(1), 114-133.

Mayes, T., \& De Freitas, S. (2004). Stage 2: review of e-learning theories, frameworks and models. JISC e-Learning Models Desk Study Issue 1. Retrieved from https://www.webarchive.org.uk/wayback/archive/20081225004835/http://www.jisc.ac.uk/whatwe do/programmes/elearningpedagogy/outcomes.aspx

Miller, W., \& Rollnick, S. (2013). Helping people change (3rd ed.). New York: Guildford Press.

Ofcom. (2016). Children and parents: Media use and attitudes report. Retrieved from https://www.ofcom.org.uk/ data/assets/pdf file/0034/93976/Children-Parents-Media-UseAttitudes-Report-2016.pdf

Rafferty, J. (2014). Foreword. In J. Westwood (Ed.), Social media in social work education (pp.ix - xi. Northwich, UK: Critical Publishing.

Reamer, F. G. (2013). The digital and electronic revolution in social work: Rethinking the meaning of ethical practice. Ethics and Social Welfare, 7(1), 2-19.

Riggall, S. (2011). Social work students' experiences of using the Egan skilled helper model. Journal of Practice Teaching and Learning, 11(1), 37-53.

Riggall, S. (2015). The sustainability of Egan's skilled helper model in students' social work practice. Journal of Social Work Practice, 30(1), 81-93.

Schraer, R. (2015, April 29). Less than $2 \%$ councils provide social media guidance for social workers. Community Care. Retrieved from https://www.communitycare.co.uk

Science and Technology Committee. (2016). Digital skills crisis. Second report of session 2016-17 [HC 270]. Retrieved from http://dera.ioe.ac.uk/26605/1/270.pdf

Sussex Innovation Centre. (2016). Social work education apps: Market analysis. Unpublished, Sussex Innovation Centre, University of Sussex.

Susskind, R. E., \& Susskind, D. (2015). The future of the professions: How technology will transform the work of human experts. Oxford, UK: Open University Press.

Taylor, A. (2016). Social work and digitalisation: Bridging the knowledge gaps. Social Work Education, 36(8), 869-879.

Turner, D. (2014)_Creating \#team turner: an autoethnography of connection within social work education. In: Westwood, Joanne (ed.) Social media in social work education. Critical Publishing, Northwich

Turner, D., Bennison, G., Megele, C., \& Fenge, L., (2016) Editorial: Social work and social media: best friends or natural enemies? Social Work Education, 35 (3), 241-244.

Turner, D. (2016). 'Only connect': unifying the social in social work and social media. Journal of Social Work Practice, 30 (3), 313-327.

Wahab, S., Trimble, J., Mejia, A., Mitchell, S. R., Thomas, M. J., Timmons, V., Waters, A. S., Raymaker, D., \& Nicolaidis, C. (2015). Motivational interviewing at the intersections of depression and intimate partner violence among African American women. Journal of Evidence-Based Social Work, 11(3), 291-303. 
Wheeler, S. (2015). Learning with e's: Educational theory and practice in the digital age. Wales: Crown House Publishing. 